\title{
Regional anesthesia: an elegant way to circumvent the "trouble" amidst the COVID I9
}

\section{Letter to editor}

Notwithstanding the COVID -19 pandemic, anesthesiologists are expected to deliver duties for emergencyand lifesavingsurgery. This letter is to outline the optimistic and constructive role regional anesthesia (RA) plays in these constrained and testing circumstances. To give an illustration of what we mean, we put forth this case of a91-year-old lady who has approvedof reporting of thecase. She was brought to the hospital with left ankle bimalleolar fracture with an open wound as a consequence of a fall. She was posted for closed reduction with CAST fixation. Concomitantly, she had complaints of breathlessness for onemonth which increased since last week attributed to interstitial lung disease (ILD). The idiopathic pulmonary fibrosis was diagnosed 4 months back HRCT (interstitial segmental thickening and traction bronchitis with sub pleural honey combing). She had suffered from ischemic heart disease and operated for CABG -3 years back. Presently the 2D echo reported - EF-40\%, RWMA +, grade $1 \mathrm{DD}$, IHD with moderate LV systolic dysfunction.

The close reduction was done under a US guided sciatic and femoral nerve block. The sciatic nerve block was administered in the right lateral position. She was turned supine for femoral block. The procedure was done under strict precautions, standard monitoring and oxygen supplementation via nasal prongs.

We take an opportunity to proffer the role of RA potentially in OR especially in the current COVID -19 times.Apart from the added benefits that we are aware of, RAsure has more to offer at the current time.

Firstly, the Anesthesiologists and other perioperative care providers are particularly at risk when providing respiratory care and tracheal intubation of patients with COVID-19.,

Secondly, the testing is limited at least in our scenario and we could never be too sure of the infectivity status of a person.

That said, the least we could do is to choose our anesthesia reasonably well. Avoid tracheal or any airway instrumentation and make liberal use of regional anesthesia.

On this occasion, we would like to propose that RA should be more protective for the patients, and to the anesthesiologist as well. We can do away with tracheal intubation or any airway instrumentation which general anaesthesia makes mandatory. To put it another way, GA should be reserved when necessary and we suggest RA could be a
Volume 12 Issue 3 - 2020

\author{
Vrushali Ponde, 'Y Venkata Naga Sahithya, ${ }^{2}$ \\ Tripti Nagdev, ${ }^{3}$ Antao Nicholas ${ }^{4}$ \\ 'Consultant, Department of anaesthesia, India \\ ${ }^{2}$ Senior Resident, Department of anaesthesia Holy Spirit \\ Hospital, India \\ ${ }^{3}$ Fellow, National university hospital, Singapore \\ ${ }^{4}$ HOD Orthopaedic surgery, Department Holy Spirit Hospital, \\ India
}

Correspondence: Vrushali Ponde, Consultant, Department of Anaesthesia, Mumbai, India, Email vrushalipone@yahoo.co.in

Received: April 30, 2020 | Published: June 12, 2020

better alternative with its virtue of minimized handling of the airway and reduce the airbone spread of COVID-19. ${ }^{3}$

We have one more reason to be proactive in practising RA in current time!

\section{Acknowledgments}

None.

\section{Conflicts of interest}

None.

\section{References}

1. Caputo KM, Byrick R, Chapan MG, et al. Intubation of SARS patients: infection and perspectives of healthcare workers. Can J Anaesth. 2006;53(2):122-129.

2. World Federation Of Societies of Anaesthesiologists . Coronavirus guidance for anaesthesia and perioperative care providers.

3. Chan J, Yuan S, Kok K et al. A familial cluster of pneumonia associated with the 2019 novel coronavirus indicating person-to-person transmission:a study of a family cluster. Lancet. 2020; doi:10.1016/S01406736(20)30154-9. 